دراسة مقارنة للتوجهات الفاسفية للتوافق الدراسي على وفق المتغيرات البيوغرافية لطالبات

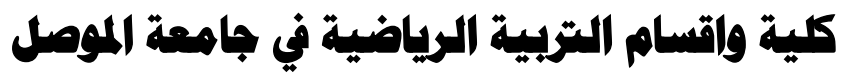

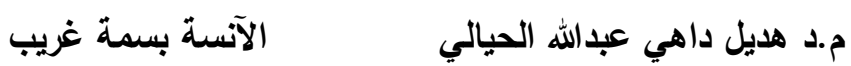

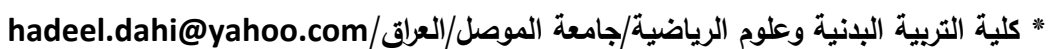

\title{
unity
}

يهذف البحث للتعرف على التوجهات الفلسفية للتوافق الدراسي لطالبات كلية وأقسام التربية الرياضية في جامعة الموصل.

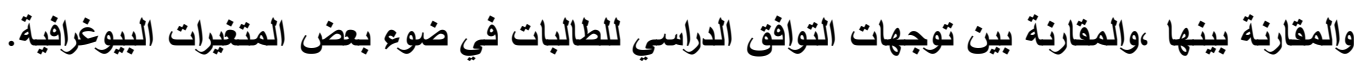

وتم استخدام المنهج الوصفي بطريقة المسح لملائمته وطبيعة البحث. واختير مجتمع البحث بالطريقة العدية والمتمثلة

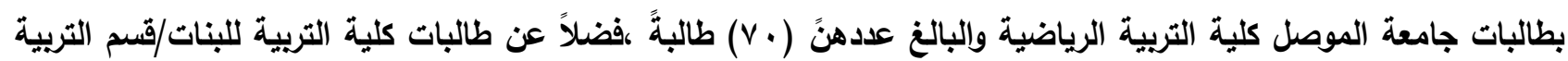

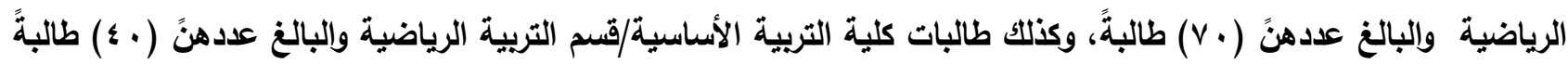

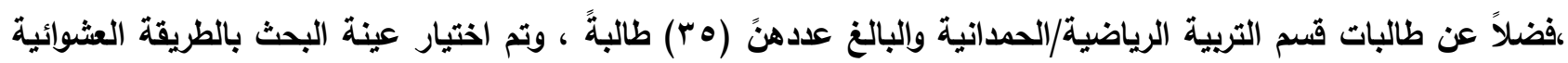

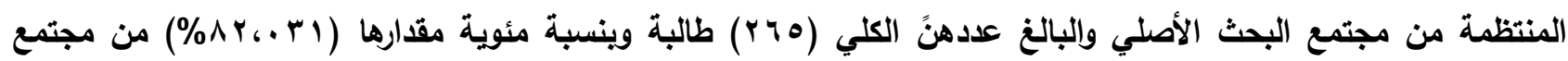

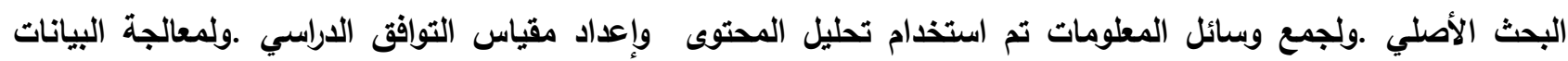
إحصائية تم استخدام( النسبة المئوية ، والوسط الحسابي ، والانحراف المعياري ، واختبار T للعينات غير المتساوية ،وتحليل التباين) عن طريق الحقيبة الإحصائية( spss ). ومن عرض النتائج ومناقشتها تم استنتاج إن طالبات كلية وأقسام التربية الرياضية لديهنً توافق دراسي ، وان طالبات كلية التربية الرياضية لديهن توافق دراسي أفضل من طالبات أقسام التربية الرياضية في جامعة الموصل. وأوصت الباحثتان في ضوء الاستنتاجات بضرورة توانيه لفيل الأنثطة اللامنهجية الهادفة لتعزيز التوافق بين جميع الطلبة. و تفعيل مكتب التوجيه والإرشاد في الجامعة للطلبة المستجدين ووصوهل فوا إلى الخريجين.

A comparative study of the philosophical Attitudes for the academic harmony according to biographical variables for the students of the College and departments of Physical Education and at the University of Mosul Dr. Hadeel Dahi Abdullah Al- Hayali Ms. Basma Ghareeb

The research aims to identify the philosophical attitudes for the academic harmony for the students of the College and departments of Physical Education and departments at the University of Mosul. Then compare between them, and to comparison of academic compatibility directions for students in light of some of the biographical variables.

Descriptive method was used with survey style for its to suitability and the nature of the search. and was selected the research community intentional which reaper seated the college and departments of the University of Mosul (College and departments of Physical Education and of their number (70) students, and students of the College of Education for Girls / Department of Physical Education and of their number (70) students, and students of College of Basic Education / Department of Physical Education and of their number (40) student, and students Department of Physical Education / Hamdania and of their number (35) student, The research sample was choose systematic random from the community of original research and of their number (265) students and the percentage of $(82.031 \%)$ of the original s research. and to collect and means of information has been Using content analysis and scale setting 
compatibility mode. Data processing statistical has been used (percentage - the arithmetic mean _ standard deviation - a test $T$ for the samples is equal, and analysis of variance) by courier statistical spss., and viewing the results and discussion was concluded that the students College and departments of physical education to have agree semester, and students Faculty of Physical Education to have compatibility study the students of the departments of Physical Education at the University of Mosul. The researchers recommended in light of the findings need to activate the extracurricular activities that aim to enhance compatibility among all students., and activate the Office of guidance and counseling at the university for new students through to graduates.

1-التعريف بالبحث

1- 1 - المقدمة وأهمية البحث

ان القرن الحادي والعشرون يتميز بالتطور الهائل والتقدم المتسارع، الذي لم تعرف البشرية له مثيلاً من قبل، من

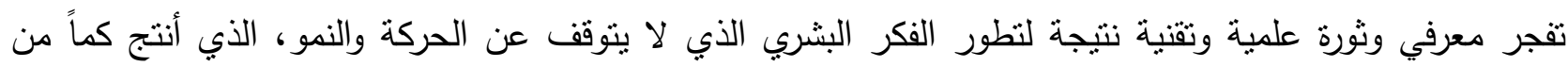
المعلومات الرقمية، وتغيراً في التقنيات، وتحولاً في المهن، ولذلك لابد للفكر التربوي من تبني توجهات فلسفية للتربية المستمرة وهي اتجاه جديد في التربية جاءت لتلبي حاجة أوجدها المجتمع وكحل للمشكلات التي أفرزتها المنجزات الحضارية ومتطلباتها الهادفة إلى استمرار التحسن نحو الأفضل والحصول على أعلى أنشكال تحقيق فاعلة في مجال التربية لبناء جيل منوافق مع ذاته من جهة ومع التطورات التكنولوجية والتغيير المتسارع الذي يحدث في العالم. وتعد العديد من الدراسات صورة الطالبات على أساس أن هذه الصورة تعكس مدى الوعي بدور الطالبة في المواقع المختلفة، وأن الصورة التي يكونها قطاع من المجتمع عن المرأة تمثل استجابة لدورها، وهذه الصورة إما تدعيم لدورها أو الكف له ـ لذلك يعد التعليم الجامعي أحد الأدوار المساعدة التي تساعد في زيادة وتعظيم دور مساهمة الطالبة في تقدم المجتمع ، فالتعليم الجامعي أحد الركائز الذي يعتمد عليها المجتمع، فهو الأساس في تقدمه وتطوره، ويقاس تطوره بسرعة استجابته وتجاوبه مع المتغيرات الاجتماعية والتحديات التربوبة التي يطرحها مجتمع المعلومات، ويتوقف نجاح العملية التعليمية على العديد من العوامل التي تتطلب السعي المستمر والجاد لاستيعابها والإلمام بها، ويعد الطالب لهاب

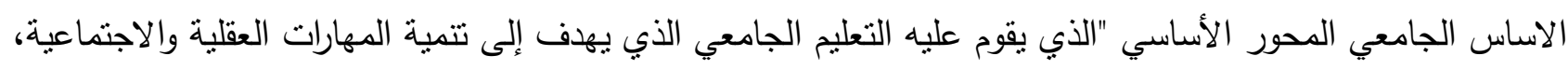

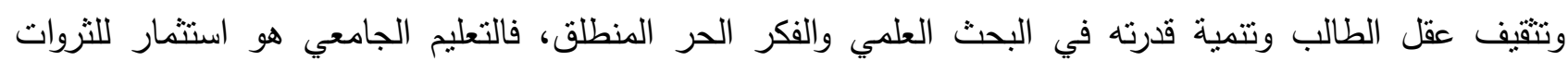

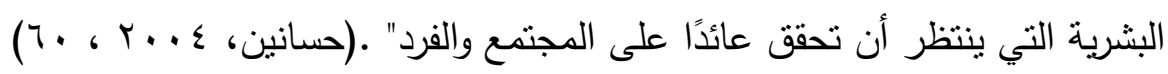
ويعد" التوافق الدراسي من أهم أنواع التوافق التي يتطلبها إنسان العصر الحالي ذلك أن الفرد يجلس أكثر من عشرين سنة في مقاعد الدراسة ، سيما وأن الإنسان وحدة كلية لا يمكن تجزئتها ، وأن ما هو عقلي معرفي يؤثر فيما هو وجداني

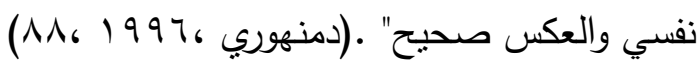
من هنا برزت أهمية البحث في الوقوف للتعرف على توجهات التواقق الدراسي لطالبات كلية واقسام التربية الرياضية في جامعة الموصل في ضوء بعض المتغيرات البيوغرافية ـ أملين أن بسهم هذا الجهذ في توجيه انتباه 
الباحثين، والمختصين، وأصحاب القرار إلى الوسائل الفعالة التي يمكن من خلالها مواجهة الصعوبات التي تعترض حياة الطالبة الجامعية، لتقوم بدورها المتوقع منها، بما تبدع فيه من مجالات أدبية وعلمية.

r-1 r r r مشكة البحث

تعد الطالبة الجامعية إحدى أعضاء المجتمع إذ تسهم بدور فاعل و أساس في بنائه وتقدمه، وذلك بعد أن تتال

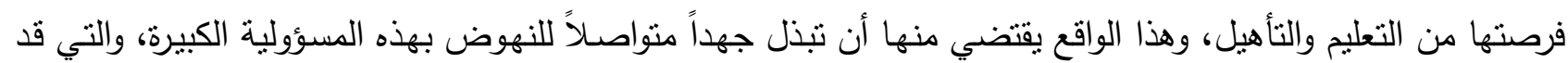
تكون مضـاعفة بالنسبة للطالبـات اللاتي تزوجن قبـل إتمـام دراستهن الجامعيـة، فالاهتمـام بالطالبـات الجامعيات يعني الاهتمام بالفئة التي تنتكل منها غالبية أفراد المجتمع بشكل عام، والواقع الحالي للتعليم الجامعي في العراق يشهـ زيادة ملحوظة في أعداد الطالبات المقبولات في كلية واقسام التربية الرياضية ، مما يثير التساؤل عن مدى التوافق الدراسي لديهن، ضمن متغيرات العمر والحالة الزوجية والمستوى الثقافي للوالدين وغيرها من المتغيرات البيوغرافية ، حيث كانت

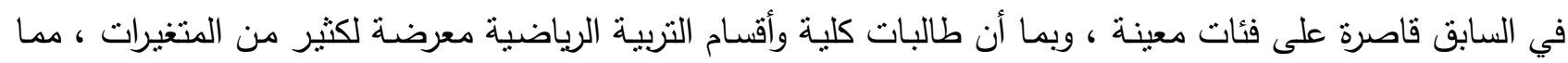
قد يؤثر في مستوى توافقها الدراسي، إذ تقع عليهنً مسؤوليات كثيرة منها ما يتعلق بشؤون الزوج وتربية الأبناء إذا كانت

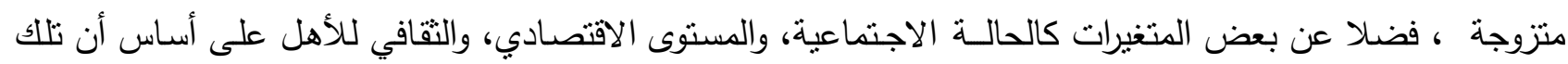
المتغيرات تمثل أهم جوانب الحياة لدى الطالبة ، التي قد تساعدها على تحقيق التوافق الدراسي، وهنا ترى الباحثتان أن البيئة العربية تختلف عن الثقافة الغربية، حيث أن الأسرة لا تشكل عاملاً مسانداً تجاه الطالبـات وبالتالي فهم يواجهنً أحداث الحياة ويستسلمون لهنً ، وقد لا يستطيعوا التوافق مـع منطلبـاتهنً الجامعيـة لأنهنً لا بلقون القبول الاجتمـاعي لسلوكهنً. من هنا تبرز مشكلة البحث في التساؤلين الآتيين : ا - هل طالبات كلية التربية الرياضية لديهن توجهات فلسفية للتوافق الدراسي أفضل من طالبات اقسام التربية الرياضية

r - هل طالبات اقسام التربية الرياضية يمتلكنا توافق دراسي ؟ ץ- هل للمتغيرات البيوغرافية تأثنر على التوافق الدراسي؟

$$
\begin{aligned}
& \text { ا - أهداف البحث } \\
& \text { يهذف البحث للتعرف على : }
\end{aligned}
$$

1- التوجهات الفلسفية للتوافق الدراسي لطالبات كلية وأقسام التربية الرياضية في جامعة الموصل. r- المقارنة بين التوجهات الفلسفية للتوافق الدراسي بين طالبات كلية وأقسام التربية الرياضية في جامعة الموصل . ץ-المقارنة بين التوجهات الفلسفية للتوافق الدراسي للطالبات وفي ضوء بعض المتغيرات البيوغرافية (الحالة الاجتماعية ،التحصيل الدراسي للوالدين ،المستوى المعاثي ،وضعية الوالدين ،عدد أفراد الأسرة). 


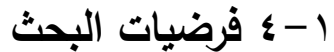

1- تتمتع طالبات كلية واقسام التربية الرياضية في جامعة الموصل بتوافق دراسي معنوي . r- نوجد فروق معنوية بين طالبات كلية التربية الرياضية وطالبات اقسام التربية الرياضية بالتوافق الدراسي ولمصلحة

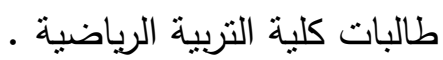
r- توجد فروق بين الطالبات بالتوافق الدراسي وبحسب طبيعة المتغير البيوغرافي ·

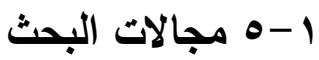

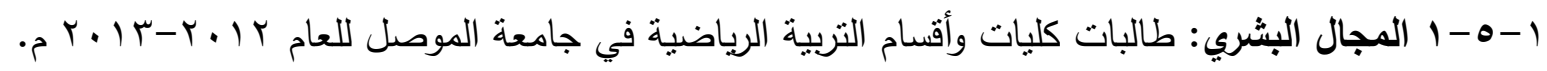

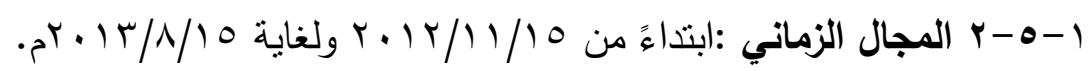
1-ه-r المجال المكاني: كلية التربية الرياضية ، وكلية التربية للبنات /قسم النربية الرياضية ،وكلية النربية الاساسية

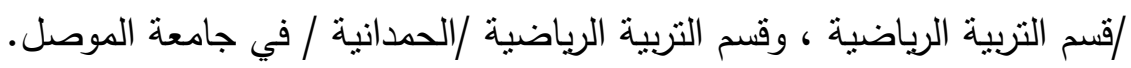

1- 1 - 1 ت تحديد المصطلحات

1-1 1-1 التوجهات الفلسفية:

عرفها كليد كلوكهوهن : أنها عبارة عن مجموعة من الافتراضات المترابطة تتضمن قيما وعناصر وجودية...وما دامت أن عناصر القيمة والعناصر الوجودية التابعة لها متمازجة بطريقة لا يمكن لها أن تتفصم عن الصورة الكلية للخبرة

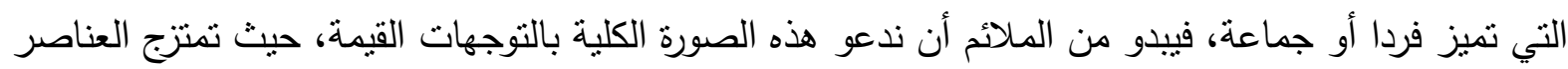

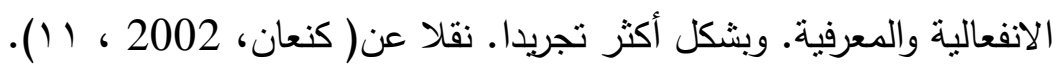

ويمكن تعريفها إجرائيا بانها الببادئ المنظمة والمحددة على الرغم من تعقيدها إذ تتتج من تفاعل ثلاثة عناصر متميزة تثترك في العملية التحليلية، وهي العنصر العقلي، والانفعالي ، والدافعي.

1-

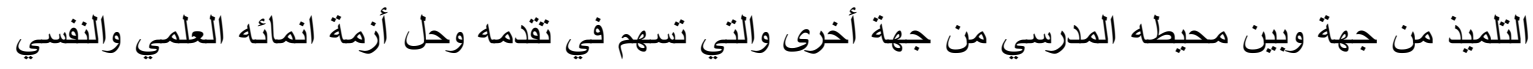
ايجابيا.( الثربيني وبلفقيه، (V)

وعرفه (بيكر وسيرك ، ؟ . . F ) بأنه "حالة تبدو من الديناميكية المستمرة التي يقوم بها الطالب لاستيعاب مواد

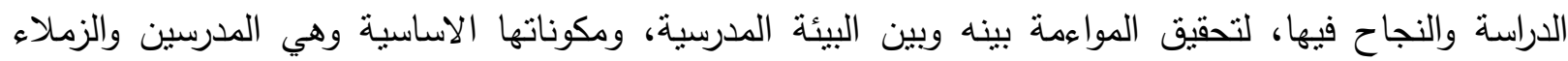

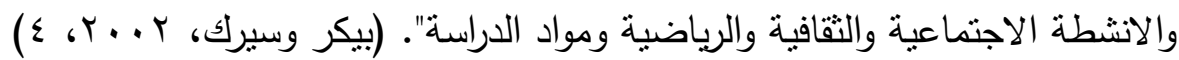
التعريف الإجرائي لتوجهات التوافق الدراسي: هو الدرجة التي تحصل عليها الطالبة من خلال الإجابة عن فقرات

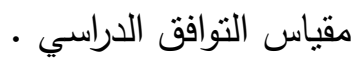


تتنتمل في العادة على الحصر الثنامل أو غير الثنامل من البيانات البيليوجرافية ومصادر المعلومات المستقلة حول

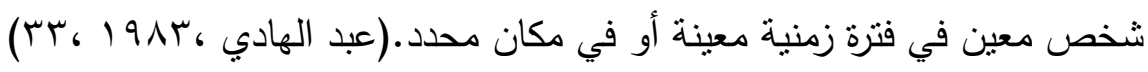

r - ب الدراسات النظرية والدراسات المشابهة

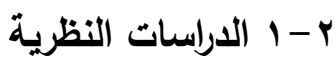

r-1-1 مقدمة التوجهات الفلسفية في التربية الرياضية :

هناك مسافة بين ما يتم عمله وما يجب عمله هذه المسافة تمثل طموح الإنسان ورغبته في الوصول للكمال وهذه

المسافة ليست ثابتة ، بل منطورة ومتغيرة تتفاعل مع كل عصر حسب منجزاته وتطلعاته وإمكانياته وتقنياته .

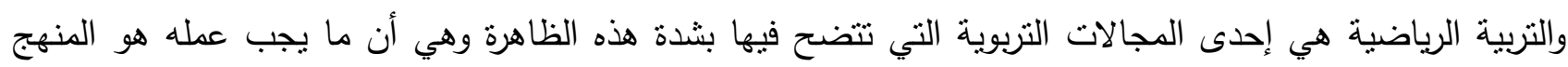

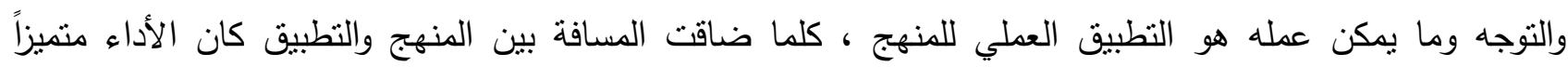
والإنجاز رائعاً من خلال تحقيق أهداف المنهاج وفي حالة اتساع هذه المسافة فإن الواقع العملي التطبيقي يكون مندنياً

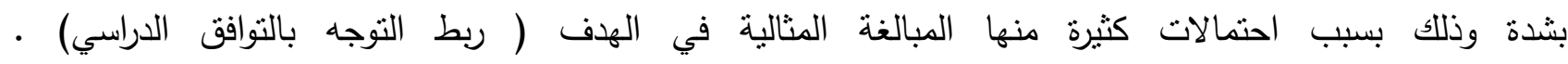

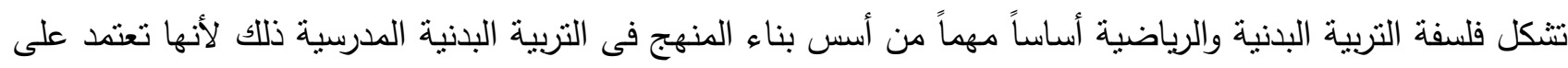

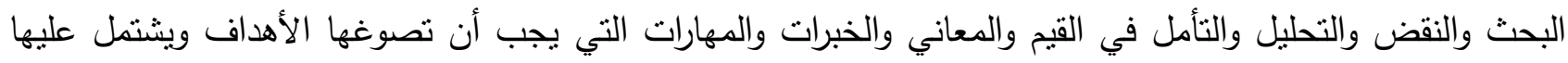

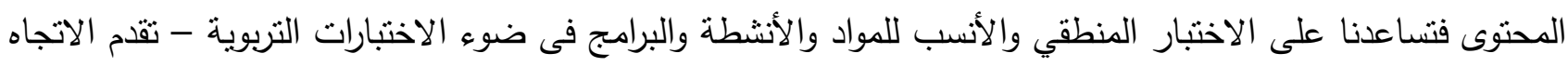

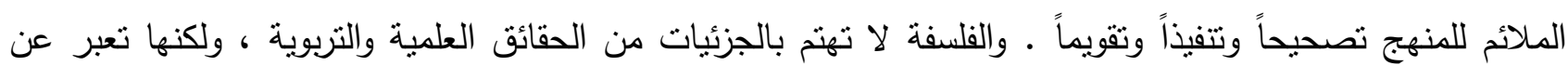
الطرائق الخاصة الني تتظم لهذه الحقائق بحيث تضفي عليها المعنى وتسوغ وجودها وتطبيقها في الحقل التربوي .

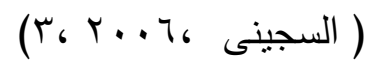

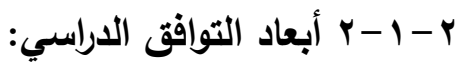

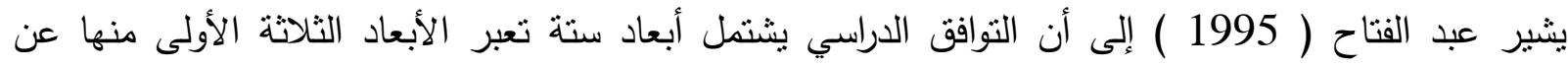

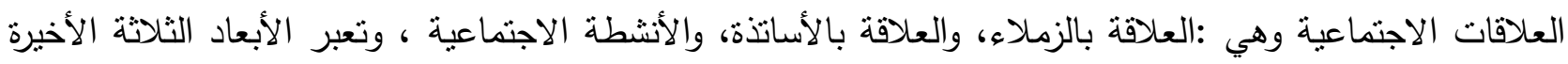

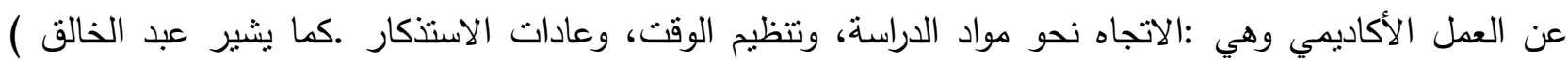

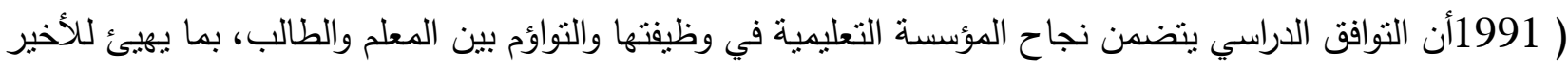

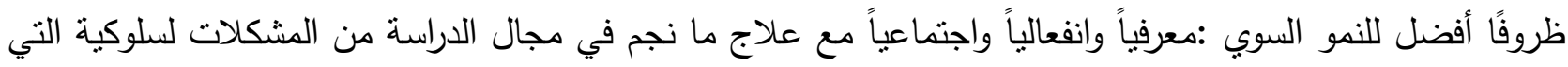

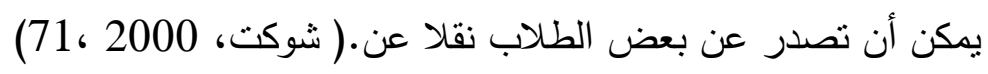




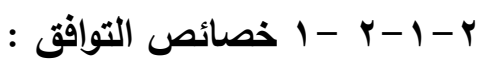
لقد أثار الباحث دمنهوري ( 1996 ) إلى ست خصائص للتوافق ، هي كالآتي:

1- التوافق عملية كلية التوافق يشير إلى الدلالة الوظيفية لعلاقة الإنسان بوصفه كائنا" حيا يتفاعل مع بيئته المحيطة بكيانه كله، ويعد التوافق بناءً على ذلك الخاصية المميزة لهذه العلاقة الكلية ، فالاتساق بين جزئيه من مكونات الإنسان

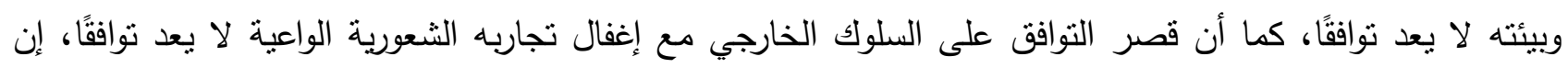

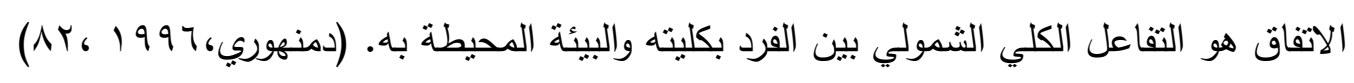

r- التوافق عملية ديناميكية:

التوافق لا يتم دفعة واحدة وبصفة نهائية ، ولكنه يستمر ما استمرت الحباة، فالحياة ليست سوى سلسلة من

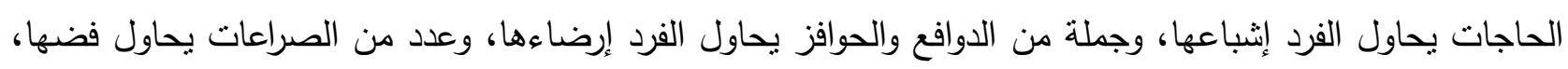

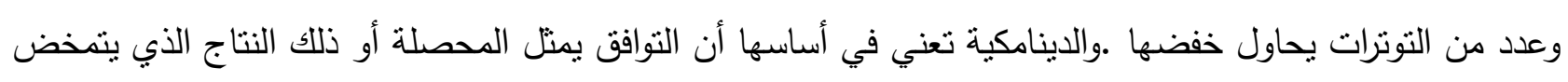
عنه صراع القوى المختلفة بعضها ذاتي والآخر بيئي، كذلك فإن بعض القوى الذاتية فطري والآخر مكتسب، والقوى البيئية كذلك بعضها مادي وبعضها قيمي وبعضها اجتماعي، والتوافق هو المحصلة النهائية لكل هذه القوى.

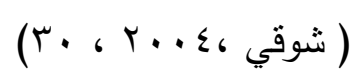

r- التوافق عملية وظيفية:

إن النوافق ينطوي على وظيفة أساسية هي تحقيق التوازن مع البيئة، وهنا الذي لا يعدو عن كونه تكييف ،فيجب أن نفرق

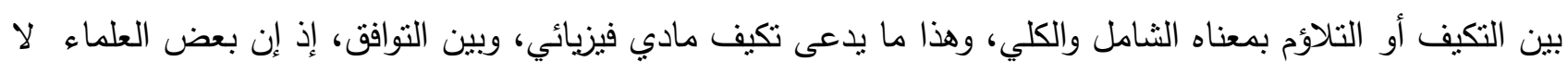

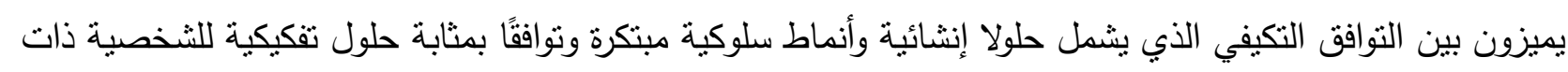

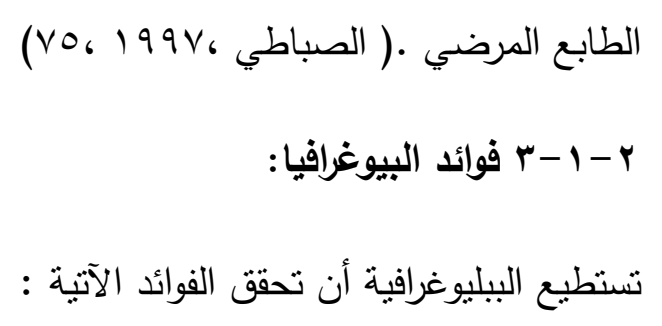

أ- تدل الباحث على المصادر الخاصة بموضوع بحثه عبر كل الامتدادات التي برغبها زمنيا ومكانياً ولغوياً وموضوعياً. ب- تساعد الباحث على الاختيار والانتقاء للمصادر التي يرغبها كما ترشده إلي مصادر لم تخطر بباله. ج- تمكن الباحث من التحقق من معلومات معينة والعمل علي استكمالها أو تصحيحها. 
د- تعتبر البيليوجرافيات مفاتيح مصادر المعلومات وهي توفر الجه والوقت والتكاليف ومن ثم يكون إنجاز الدارس لبحثه

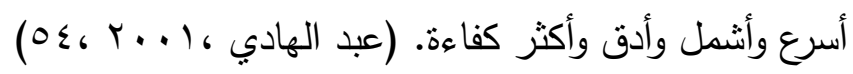

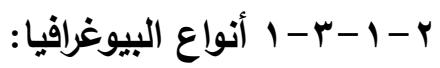

ممكن أن نقسم البيوغرافيا إلى نوعين هما: - م

أ- البيليوغرافية التحليلية النصية: يطلق عليها أحيانا البليوجرافيات النقدية وهي تشمل شرح كل الحقائق المنعلقة

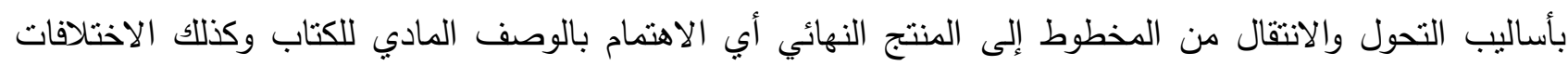
النصية بين المخطوط والكتاب المطبوع وبين الطبعات المختلفة للكتاب الواحد أو ما يسمي بناريخ حياة الكتاب الكتاب.

ب- الببليوغرافية النسقية الحصرية: وهي عبارة عن قوائم نسقية تهدف التعريف بالإنتاج الفكري الذي يصدر في نطاق

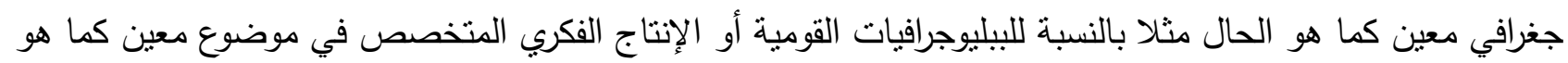

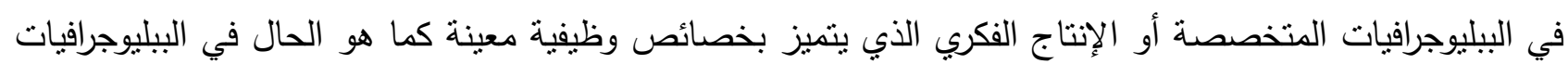

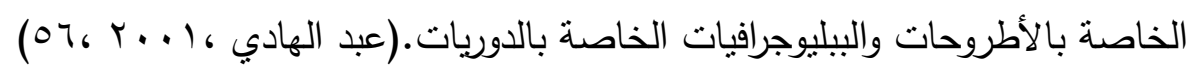

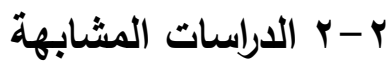

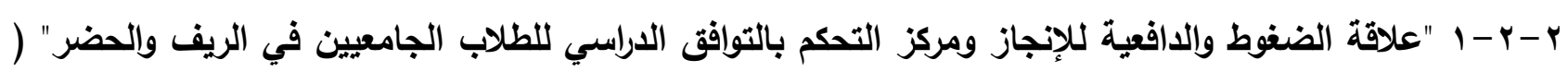

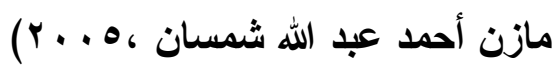
تهدف الدراسة إلى الكثف عن العلاقة بين ضغوط أحداث الحياة والدافعية للإنجاز ومركز التحكم وبين النوافق الدراسي

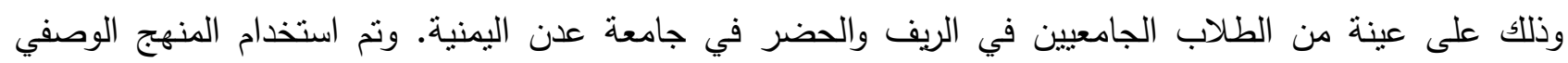

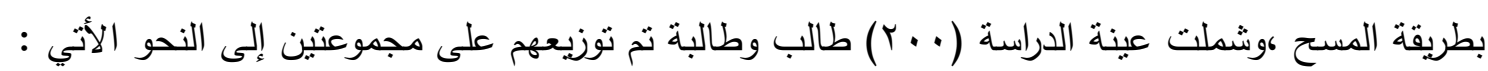

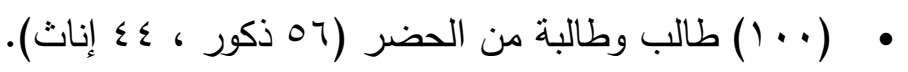

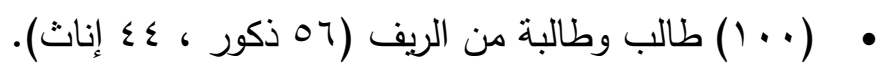

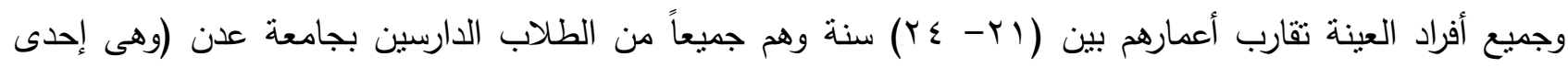

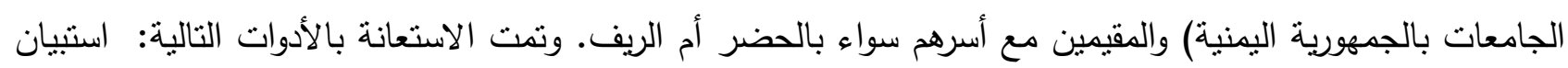

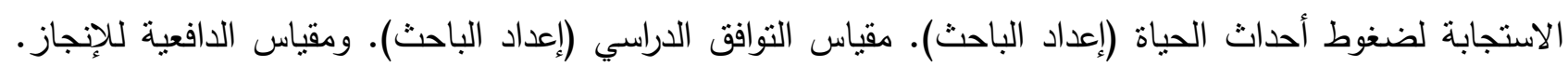

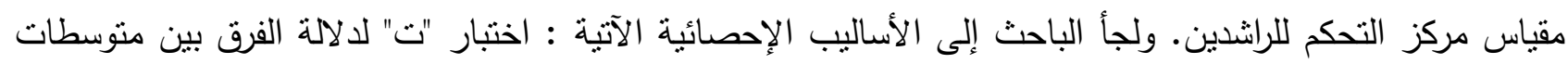

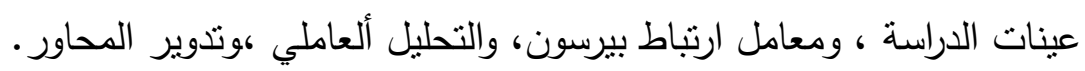

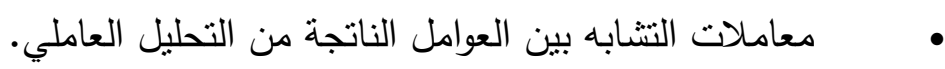

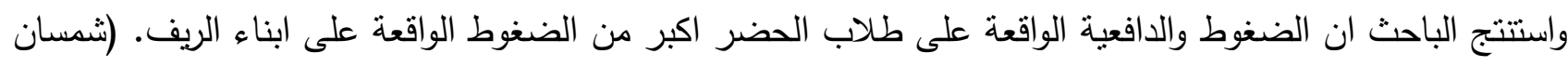
(ON, Y...0, 
r-r-r الأكاء الاخلاقي وعلاقته بالتوافق الدراسي لاى تلامذة الصف

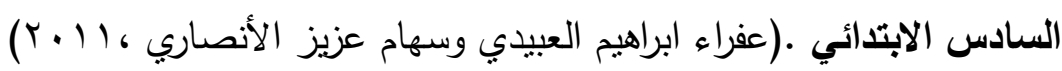
يستهدف البحث التعرف على الذكاء الاخلاقي والتوافق الدراسي لدى تلامذة الصف السادس الابتدائي فضلاً عن كثف العلاقة الارتباطية بين الذكاء الاخلاقي والتوافق الدراسي ، إذ تحدد البحث بتلامذة الصف الساد الابتدائي من كلا الجنسين من مدينة بغداد /تربية الكرخ الثانية ، إذ بلغت عينة البحث ( .0.) تلميذاً وتلميذة، ثم اعداد مقياسين احدهما لقياس الذكاء الاخلاقي والآخر لقياس التوافق الدراسي وبعد التأكد من الخصائص السايكومنرية للمقياسين تم تطبيقهما على عينة البحث ، وبعد معالجة البيانات بالوسائل الاحصائية المناسبة توصل البحث الى النتائج الاتية: ا -ان تلامذة الصف السادس الابتدائي يتمتعون بذكاء اخلاقي. r - -ان تلامذة الصف السادس الابتدائي يتمتعون بتوافق دراسي. ץ - -وجود علاقة ارتباطية موجبة دالة احصائياً بين الذكاء الاخلاقي والتوافق الدراسي لدى تلامذة السادس الابتدائي. وفي

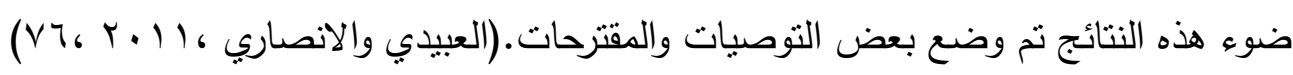
ب - براءات البحث r- منهج البحث

استخدمت الباحثنان المنهج الوصفي المسحي المقارن، لأنه من أنسب المناهج لطبيعة البحث الحالية وأهدافه، ولا يقف عند حد الوصف، بل يتعداه إلى مرحلة تفسير المعلومات وتحليلها واستخلاص دلالات ذات مغزى تفيد في الوقوف على المشكلات الأكاديمية لطالبات الجامعة في الأدبيات التربوية، ورصد الأسباب الكامنة وراء هذه المشكلات، وكذلك مستوى أدائهن الدراسي بقصد المقارنة بينهما، ومن ثم اقتراح آليات قائهة على أسس علمية من منظور تربوي قد تقيد في التغلب على تلك المشكلات.

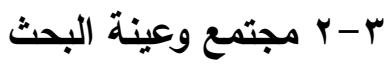

يعرف المجتمع بأنه " مجموعة العناصر والأفراد الذين بنصب عليهم الاجتماع في دراسة أو مجموعة

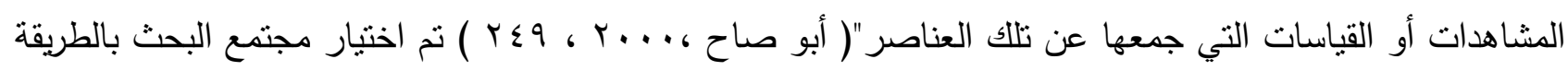
العمدية والمتمنلة بطالبات جامعة الموصل كلية التربية الرياضية والبالغ عددهنً (Av) طالبةً ،فضلاً عن طالبات كلية التربية للبنات/قسم التربية الرياضية والبالغ عددهنً (7 • () طالبةً، وكذلك طالبات كلية التربية الأساسية/قسم التربية

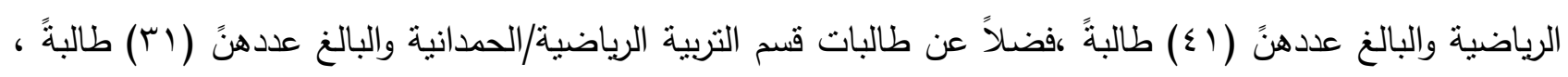

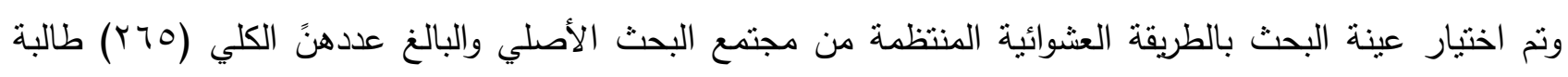

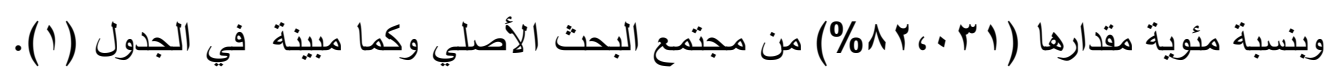


الجدول (1)

يبين مجتمع البحث وعينته

\begin{tabular}{|c|c|c|c|c|}
\hline النسبة المئوية & العينة & العدد الكلي & | الكلية & 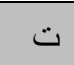 \\
\hline$\% \wedge \cdot$. $०$ ० & $v$. & $\wedge v$ & كلية التربية الرياضية & 1 \\
\hline$\%$ \%४r..rv & $v$. & 1.7 & كلية التربية للبنات & $r$ \\
\hline$\% 9 V_{6} .04$ & $\xi$. & $\leqslant 1$ & كلية تربية اساسية & $r$ \\
\hline$\%$ \% ४ 6.04 & $\mu$. & $r 1$ & الحمدانية & $\varepsilon$ \\
\hline \%Ar,.rt & ri. & ror & المجموع & 。 \\
\hline
\end{tabular}

r-r و وسائل جمع المعلومات

r-

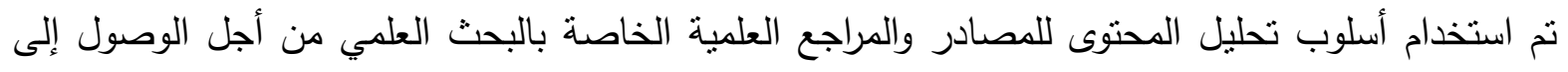

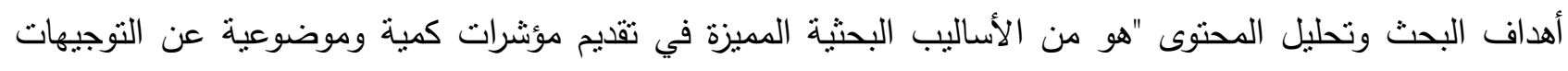

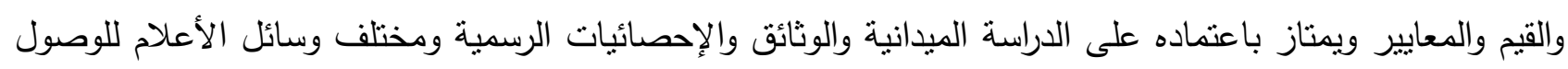

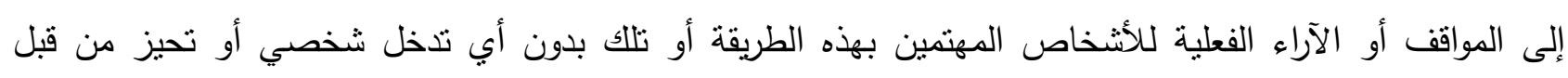

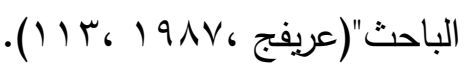

ب-r-r-r

لتحقيق أهداف البحث تطلب إعداد أداة لقياس التوافق الدراسي وفيما يأتي خطوات إعداد المقياس:

:

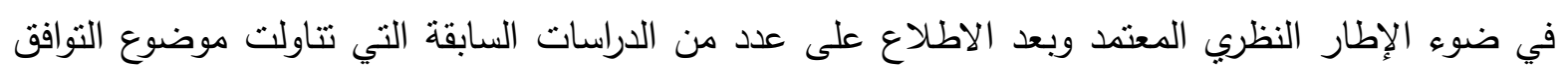

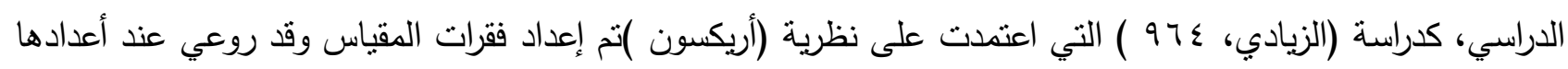

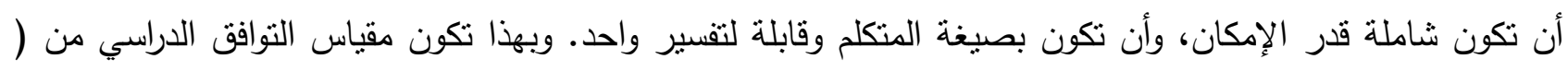
(V. r-r-r-r يقصد بصدق الأداة أن تقيس ما وضعت، لأجل قياسه، وتحقق الأهداف التي وضعت لها قبل إنبل إعدادها.(أللقاني والجمل،999 (19، 10) وتم التحقق من صدق الفقرات للمقياس عن طريق تطابق أو اقتراب الدرجات الفعلية التي حصلت

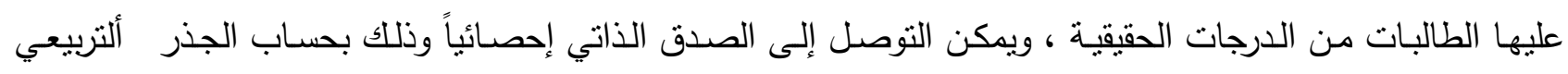

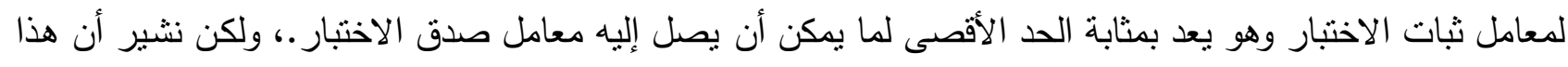

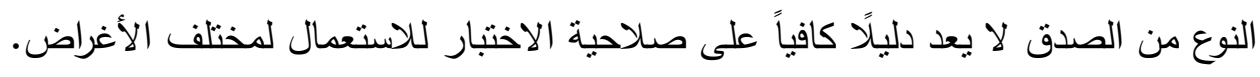


ومن أجل التأكد من صدق المقياس تم عرضسه على عدد من الأساتذة الخبراء والمتخصصين في مجال فلسفة التربية الرياضية والقياس والتقويم وعلم النفس الرياضـي وطرائق التدريسي (ملحق r) لبيان رأيهج بمدى ملائكـة وصـلاحية كل فقرة من حيث درجة موضوعيتها ووضوحها في قياس الخاصية التي وضع المقياس من أجلها ومدى ملاعمتها للمرحلة

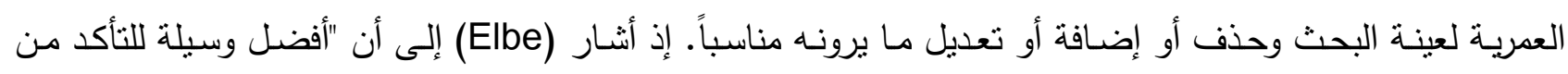
صدق الأداة هو أن يقرر عدد من المختصين مدى تغطية الفقرات جوانب الصفة المراد قياسها وشموليتها".

( Elbe, 1979,555)

:

تم الاعتماد على طريقة معامل (آلفا) كإجراء علمي للتحقق من الثبات "وهي الطريقة التي اقترحها وطورها كرونباخ

لتقدير ثبات الاتساق الداخلي وهي تعميم لمعادلة (KR-20 ) ويشيع استخدام طريقة ألفا في (مقاييس الثخصية وفي الاختبارات التحصيلية واستطلاع الرأي )وهي تعطي الحد الأدنى للقيمة التقديرية لمعامل ثبات درجات التهيت الاختبار ". إذ نم

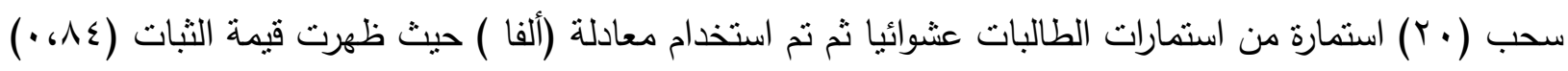

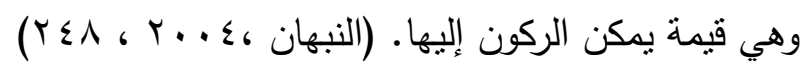
r- بـ وضوح تعليمات وفقرات المقياس ( التطبيق الاستطلاعي للمقياس) : بغية التحقق من وضوح التعليمات وفهم الطالبات لفقرات مقياس النوافق الدراسي قامت الباحثنان بتطبيق المقياس على

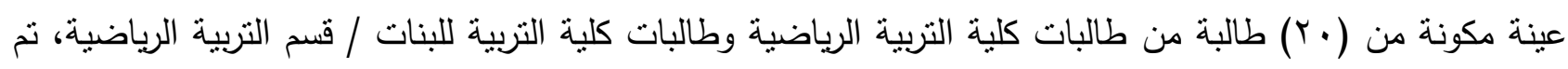
اختيارهنً بصورة عشوائية إذ بلغ عددهنً ( • ( ) طالبات من كلية التربية الرياضية ، و ( • (1 ) طالبات من كلية التربية للبنات.وتم استبعادهن من التطبيق الرئيس ، وقد كان الغرض من تطبيق المقياس للتعرف على بعض الاهداف العلمية والادارية وهي :

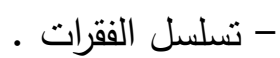
- السلبيات التي تحدث في جمع المعلومات. - التعرف على استجابة عينة البحث في الاجابة عن الفقرات . - ملائمة مفتاح التصحيح للإجابات. - الزمن المستغرق للإجابة.

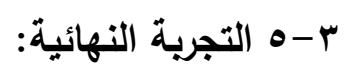
بعد استكمال الثروط العلمية للمقياس والتأكد من صلاحيته وملائمته لعينة البحث نم توزيع المقياس (ملحق ()) على

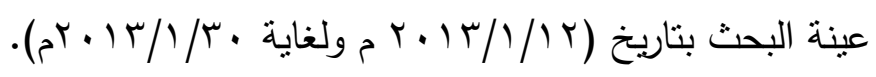


r- آو الوسائل الإحصائية:

(النسبة المئوية، والوسط الحسابي ، والانحراف المعياري ، واختبار T للعينات غير المتساوية معامل الارتباط ،

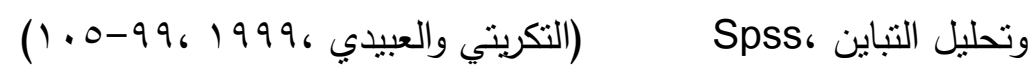

ع - عرض النتائج وتحليلها ومناقشتها

ع - إن عرض النتائج وتحليلها:

يتضمن هذا الفصل عرضا للنتائج ومناقتنها على وفق اهداف البحث وكالاتي :

الجدول ( r ) (r)

المتوسط الفرضي والوسط الحسابي والانحراف المعياري للتوافق الدراسي لطالبات كلية واقسام التربية الرياضية في جامعة الموصل

\begin{tabular}{|c|c|c|c|}
\hline المتوسط الفرضي* & الانحراف المعياري(土ءع) & الوسط الحسابي (س-) & الطالبات (عينة البحث) \\
\hline \multirow{4}{*}{1.0} & $7,79 \mathrm{~V}$ & $110, .19$ & كلية التربية الرياضية \\
\hline & $v, 1, \varepsilon$ & $11 r, .11$ & كلية التريية للبنات/قسم التربية الرياضية \\
\hline & $V, Y 0 \leq$ & $1 \cdot 1,7 \cdot 9$ & كلية التربية الأساسية/قسم التربية \\
\hline & T,OYO & $1 \cdot v, 0 \vee \wedge$ & قسم التربية الرياضية /الحمدانية \\
\hline
\end{tabular}

يتبين من الجدول (r)

إن التوافق الدراسي لطالبات كلية التربية الرياضية ظهر بوسط حسابي قدره (19 •،11 (1)) وبانحراف معياري

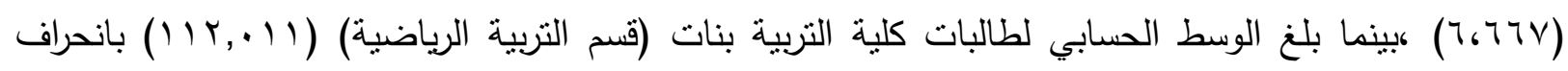
معياري قدره (ع • V, ) ، في حين ظهر الوسط الحسابي لطالبات كلية التربية الأساسية (قسم التربية الرياضية) قدره

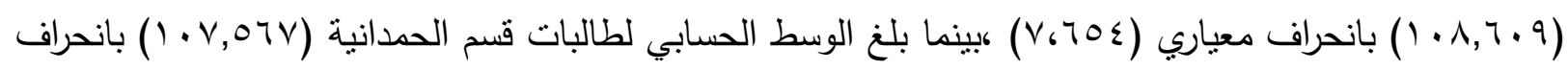

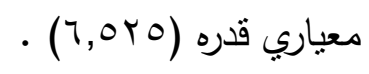

* المتوسط الفرضي = مجموع أوزان البدائل × عدد الفقرات / عدد البدائل(علاوي ورضوان ، 1991 ، 7 ـ ( ) . 


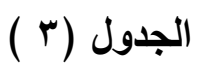

قيمة (ت) للتوافق الاراسي لطالبات كلية وأقسام التربية الرياضية في جامعة الموصل

\begin{tabular}{|c|c|c|c|c|}
\hline قيمة( Sig ) الاحتمالية & قيمة (ت) & الانحراف المعياري & الوسط الحسابي & المعالم الإحصائية \\
\hline ג &., $4 .$, & ודז,ד & $1.9,49$. & الطالبات (عينة البحث) \\
\hline
\end{tabular}

من الجدول (r) يتبين أن الن البدات

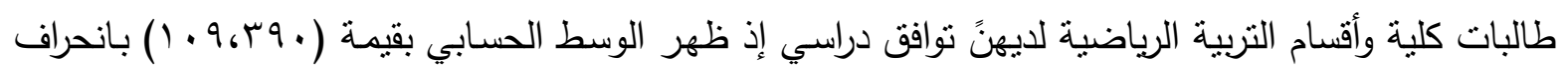

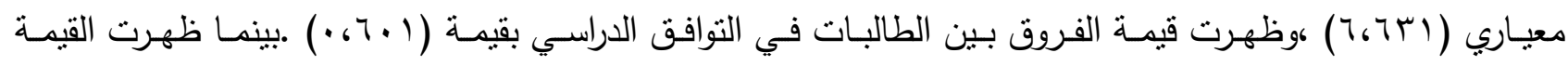

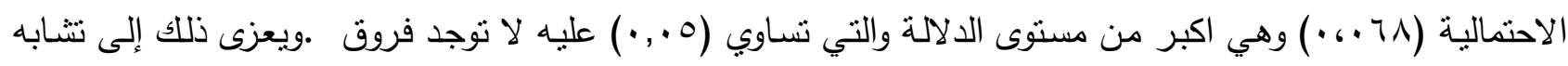

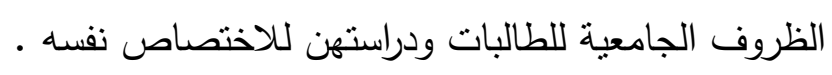

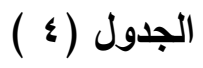

قيمة (ت) للتوافق الدراسي بين الطالبات المتزوجات وغير المتزوجات

\begin{tabular}{|c|c|c|c|c|}
\hline قيمة( Sig ) الاحتمالية & قيمة (ت) & الانحراف المعياري & الوسط الحسابي & المعالم الإحصائية \\
\hline \multirow{2}{*}{ •, } & \multirow{2}{*}{$r, v \cdot \Lambda$} & $\varepsilon, \cdot \leqslant V$ & 1.96474 & الطالبات المتزوجات \\
\hline & & $\curlyvee, . \leqslant \wedge$ & 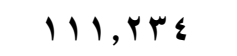 & الطالبات الغير متزوجات \\
\hline
\end{tabular}

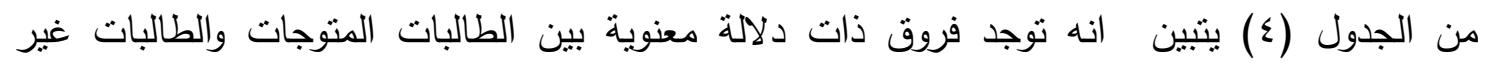

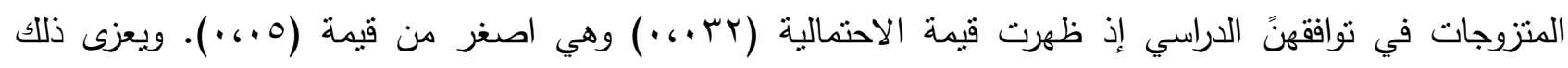

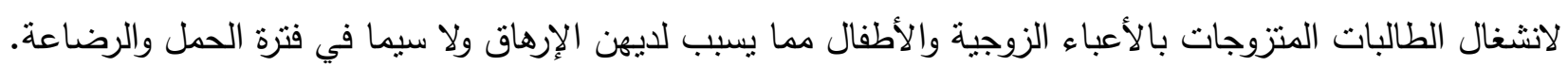

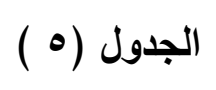

قيمة ( ت ) للتوافق الدراسي بين الطالبات وحسب المستوى التعليمي للوالدين

\begin{tabular}{|c|c|c|c|c|}
\hline قيمة( Sig ) الاحتمالية & قيمة (ت) & الانحراف المعياري & الوسط الحسابي & المعالم الإحصائية \\
\hline \multirow{2}{*}{ • } & \multirow{2}{*}{1,190} & V6.74 & 110,945 & تصافق الطالبات الاراسي لذوي \\
\hline & & $7, \cdot \leqslant \wedge$ & $11 . . .91$ & تثوافق الطالبات الدراسي بدون \\
\hline
\end{tabular}

* * ذوي الثهادات :هم أولياء الطالبات الذين لايهم شهادات الساد الإعدادي أو ما يعادلها وما فوق من بكالوريوس و......الخ . **** بدون الشهادات : هم الذين لم يكملوا الدراسة الإعدادية أو ما يعادلها . 
من الجدول( 0) يتبن انه توجد فروق معنوي بين التوافق الدراسي للطالبات اللاتي تعيش في جو اسري ذو مستوى تعليم

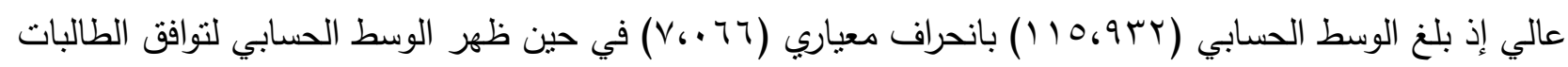

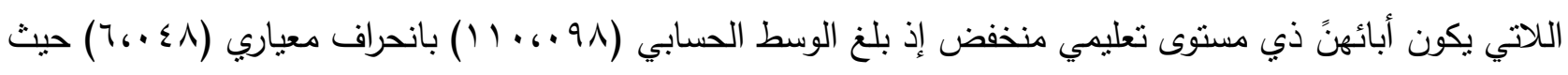

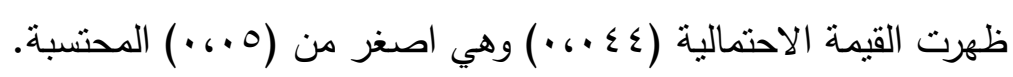

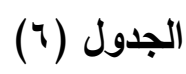

الفروقات بالتوافق الدراسي بين طالبات كلية وأقسام التربية الرياضية في جامعة الموصل

\begin{tabular}{|c|c|c|c|c|}
\hline الدلالة & تحليل التباين & مريع سكوير & درجة الحرية & مجموع المريعات \\
\hline \multirow[t]{2}{*}{$\cdot, \ldots$} & \multirow{2}{*}{ r,rar } & $r, \cdot v \wedge$ & r & 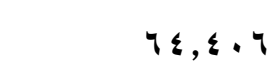 \\
\hline & & $\cdot, \wedge 79$ & $1 \leqslant$. & $|r|, 7||$ \\
\hline & & & ivi & $1{ }^{1} 4, .1 \mathrm{~V}$ \\
\hline
\end{tabular}

من الجدول (؟) يتبين لنا انه نوجد فروق معنوية بين التوجهات الفلسفية للتوافق الدراسي لطالبات كلبة التربية

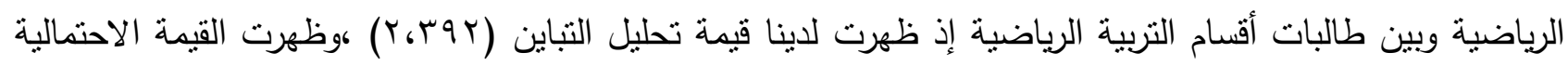

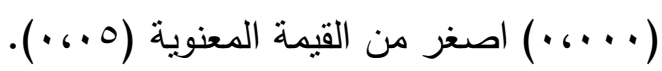

$$
\begin{aligned}
& \text { ع - r مناقشة النتائج: }
\end{aligned}
$$

من عرض وتحليل النتائج ينتين أن أفراد العينة الكلية يتمتعون بتوافق دراسي .وقد يرجع ذلك الى اجتياز

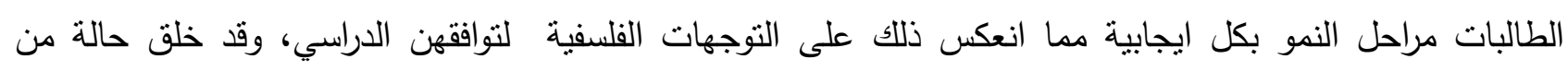

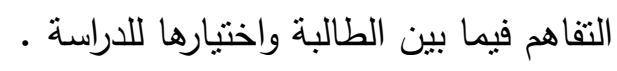

ودلت الننائج أيضا على وجود تباين في التوجهات الفلسفية للتوافق الدراسي بين طالبات كلية وأقسام التربية

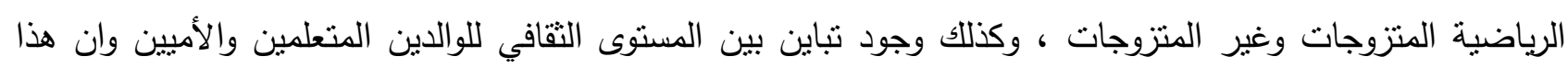

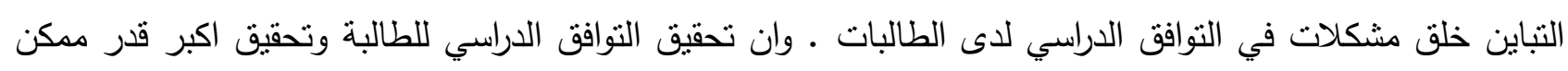

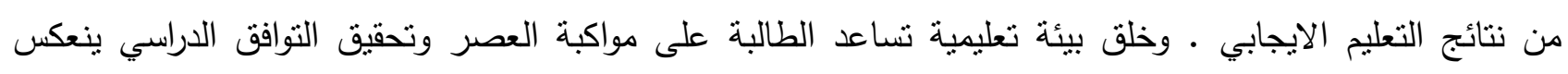

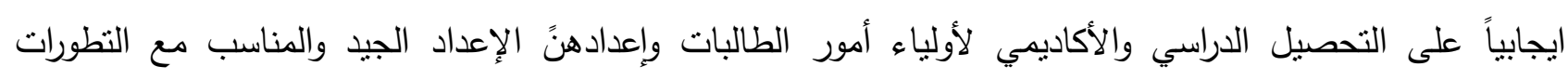

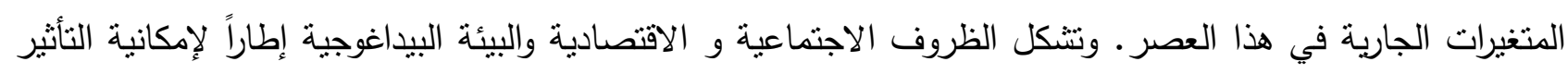

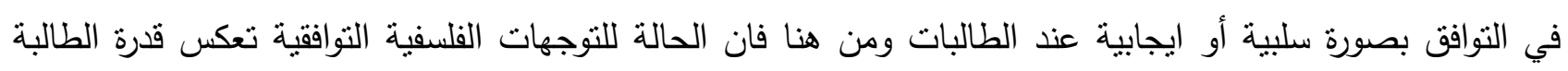

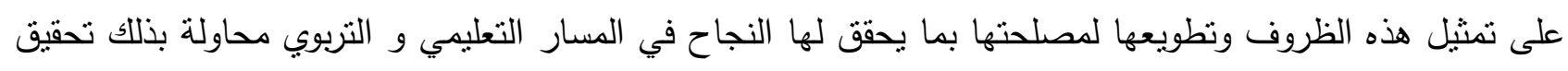
التكيف الدراسي . 
إذ تظهر دراسة وجنر وسويل (Wegner and Sewell, 1970) أن "توافق الطالب مع منطلبات الحياة الجامعية يتأثر

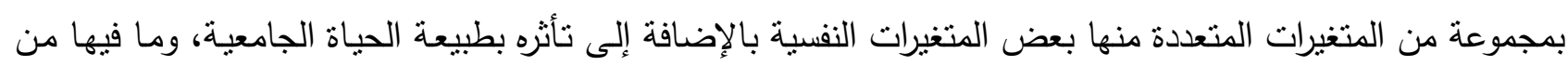

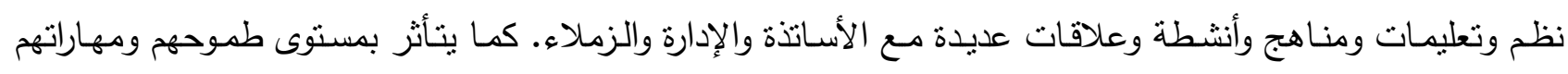

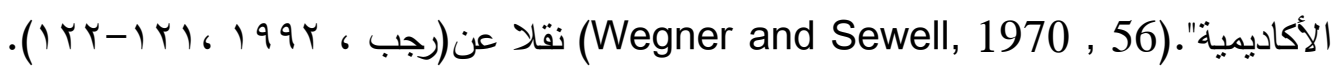

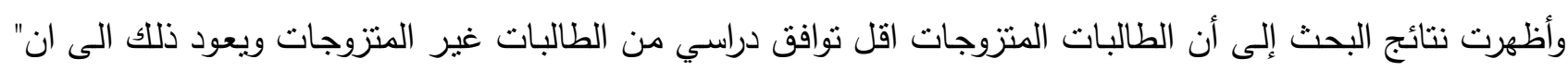

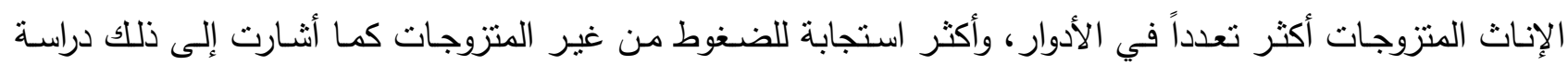

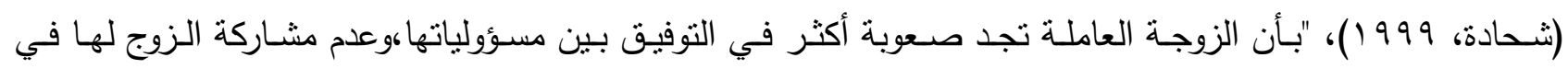

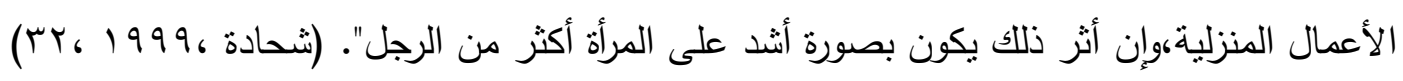

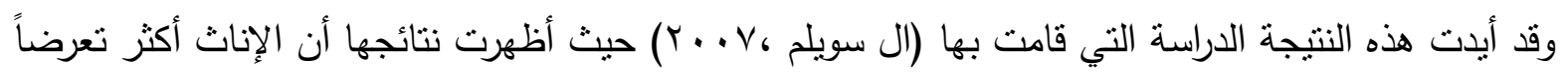

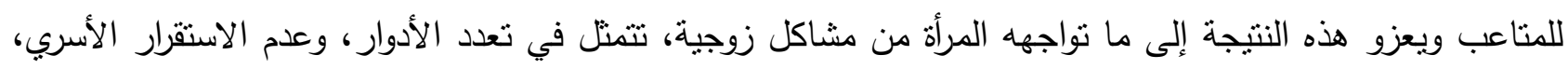

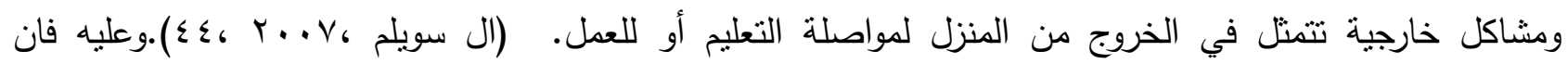

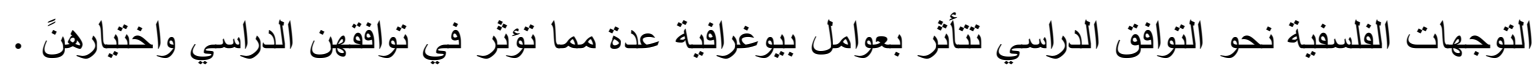
ه- الاستتتاجات والتوصيات والمقترحات

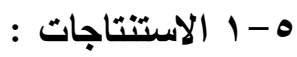

من عرض النتائج ومناقشتها تم التوصل إلى الاستتتاجات الآتية : 1 - وجود نظرة فلسفية جيدة في التوافق الدراسي لطالبات كلية وأقسام التربية الرياضية . r - توجد فروق معنوية بين التوجهات الفلسفية لطالبات كلية التربية الرياضية وطالبات أقسام التربية الرياضية. ب- التوجهات الفلسفية للتوافق الدراسي للطالبات غير المتزوجات أفضل من الطالبات المتزوجات. ع - الطالبات اللاتي يمنلك أهلهنً شهادات دراسية ويعيشون في بيئة ثقافية يمنلكنً توجهات فلسفية في التوافق الدراسي.

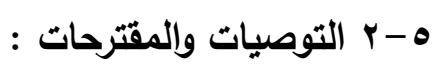

1 - الاهتمام بالمفاهيم الفلسفية للتوافق الدراسي وإنمائه بين طالبات كلية وأقسام التربية الرياضية. r- التأكيد على الأهل بتوجيه الطالبات لحسن اختبارهن للتوافق الدراسي بما يملائم الطالبات وتوجههنً الفلسفية . r- تعزيز النوجهات الفلسفية للتوافق الدراسي للطالبات الدتزوجات . ع - إجراء بحوث مشابهة على عينة الطلاب. 


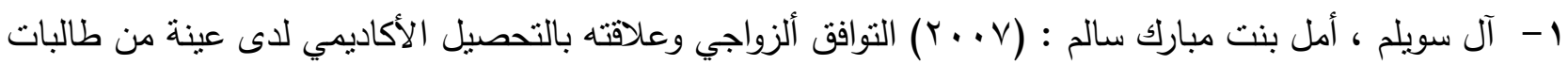

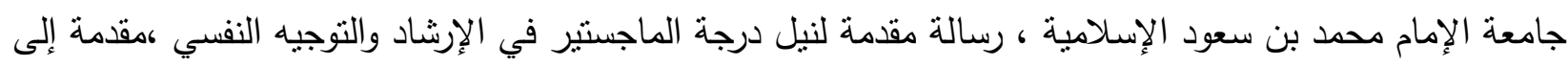
جامعة الإمام محمد بن سعود الإسلامية ، كلية العلوم الاجتماعية- الرياض.

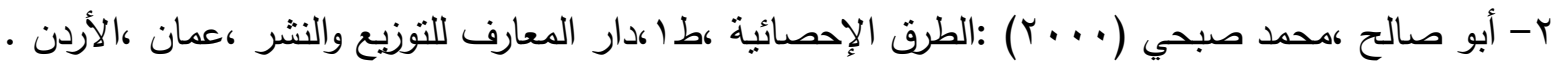
r- أبو علام، العادل (؟99 1) : التحليل ألعاملي للسلوك الدراسي المرتبط بالتحصيل الأكاديمي ."حولية كلية

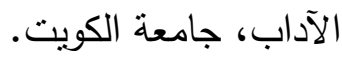

ع - بركات، زياد : (T . . Y) التوافق الدراسي لدى طالبات الجامعة دراسة مقارنة بين المتزوجات وغير المتزوجات في

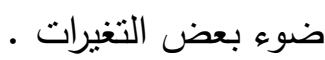

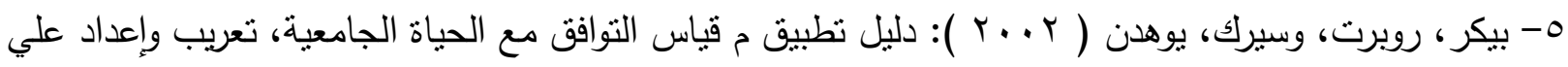

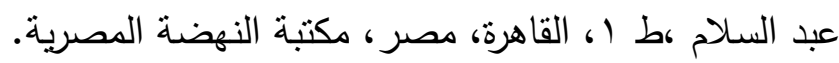

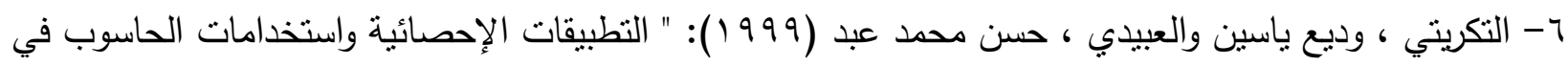
بحوث التربية الرياضية " دار الكتب للطباعة والنشر ، جامعة الموصل ، الموصل. V- حسانين، اعتدال ( 2004 ) : أساليب التفكير المرتبطة بالمواقف الدراسية والمناخ الجامعي. دراسات في علم

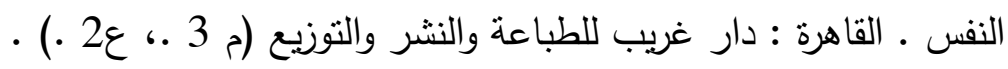
1- دمنهوري ، رشاد ( 1996 ) :بعض العوامل النفسية الاجتماعية ذات الصلة بالتوافق الدراسي • "مجلة علم النفس ـ العدد(87) القاهرة.

9- رجب ، شعبان : (ץ99 (1) دراسة العلاقة بين أساليب التعامل الأقدمية والاحجامية مع الأزمات والتوافق النفسي وبعض سمات الثخصية "،مجلة علم النفس "، العدد 7،القاهرة . • 1-الزبادي، محمود. ( (197 ). علم النفس الإكلينيكي. مكتبة الانجلو المصرية، القاهرة. 1 (1- الثربيني ، زكريا احمد وبلفقبه، نجيب محفوظ أبو بكر ( 1991 ) ): مقياس التوافق الدراسي لاى الطلبة بالمرحلة الثانوية بإمارة الفجيرة، القاهرة، مصر ، مكتبة الانجلو المصرية. r ا شحادة ، عبد المنعم (999 (199) المرأة العاملة في المجال الأكاديمي كما يراها زملاؤها ، مجلة العلوم الاجتماعية :مجلس النشر العلمي بجامعة الكويت ، م 27 .، عا ،الكويت 


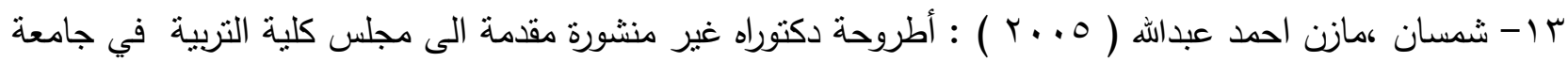
عدن باليمن .

ع ا - شوقي ، إبراهيم" ( 2004 ) الاهتمامات المهنية لطالبات الجامعة ـ " دراسات عربية في علم النفس ـ القاهرة :

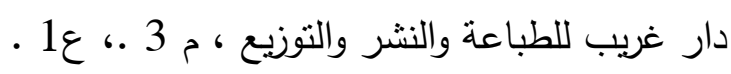

1 - شوكت ، عواطف" ( 2000 ) التوافق الدراسي لدى الطالبات المتزوجات وغير المتزوجات ، وعلاقته ببعدي الكفاية الثخصية والثبات الانفعالي • " دراسات نفسية ، القاهرة : م10 ـ ד ا - الصباطي، إبراهيم" ( 1997 ) التوافق الدراسي لاى الطلبة والطالبات السعوديين والمصريين ."المجلة التربوية، م . . 15 ، 12

V ا - عبد الهادي، محمد فتحي (T/91) : مقدمة في علم المعلومات، دار غريب للطباعة والنشر والتوزيع، القاهرة. 1 ا- عبد الهادي، محمد فتحي (1 . . r) : المصادر المرجعية في الإنسانيات والعلوم الاجتماعية.- دار الثقافة العلمية الإسكندرية . 9 ا- عريفج ،سامي: (9Avv (1 ) مناهج الحث العلمي وأساليبه ،دار مجدلاوي للنشر ، الأردن . • ץ- علاوي ،محمد حسن ،ورضوان، ومحمد نصر الدين (991 ( ):القياس في التربية الرياضية وعلم النفس الرياضي كار الفكر العربي ، القاهرة.

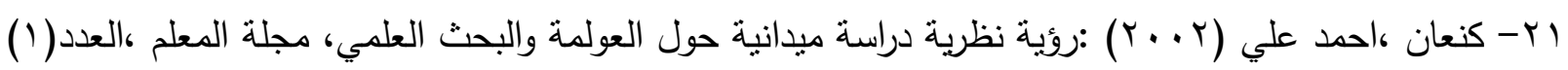
الاردن

ץ ب- أللقاني، أحمد والجمل، علي (r99 199 ) : معجم المصطلحات التربوية المعرفة في المناهج وطرق التدريس ، الطبعة الثانية ، عالم الكتب، القاهرة .

rץ- محاضرات الأستاذ الدكتورة أمل الزغبى السجينى ،لطلبة الدكتوراه بجامعة طنطا لسنة (T . . ץ ) .القاهرة . ع ז- النبهان ،موسى (ع . r) أساسيات القياس في العلوم السلوكية ،دار الثروق للنشر والتوزيع ،عمان ،الأردن. 25 - Elbe, R. I. ,( 1979) Essentials of Educational, measurement, New Jersey. Hall-Inc, Engle Wood Gifts. 
الملاحق

\section{الملدق (1)}

بسم الله الرحمن الرحيم

المحترم.

الأستاذ الفاضل

تحية طيبة:

تروم الباحثان إجراء البحث الموسوم (دراسة مقارنة للتوجهات الفلسفية للتوافق الدراسي على وفق المتغيرات

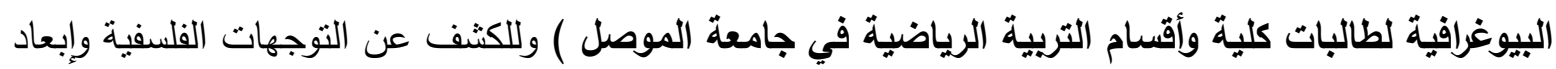

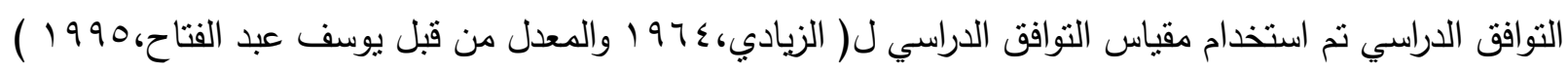

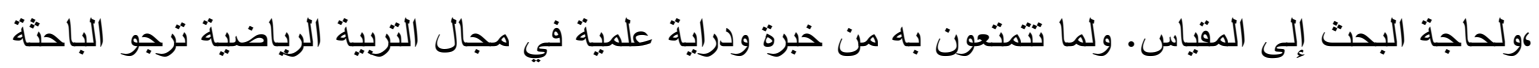

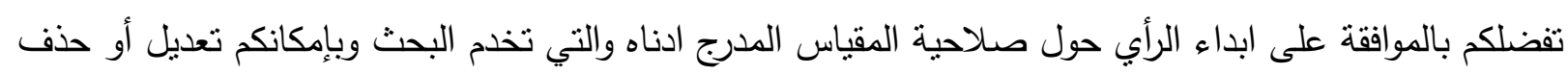
أو اضافة ما ترونه مناسبا.

\section{ولكم منا جزيل الثكر والتقلير}

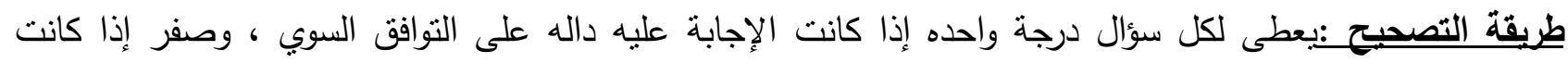

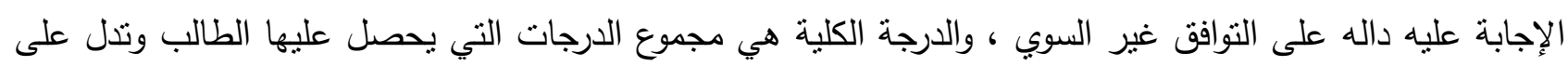

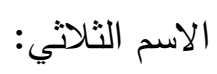

اللقب العلمي: nen

الاختصاص الاقيق:

الكلية والقسم:

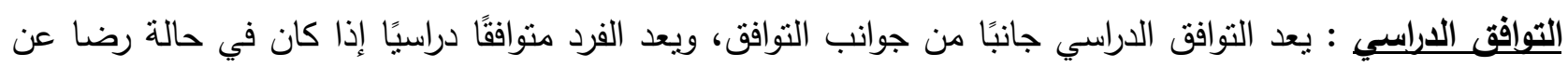

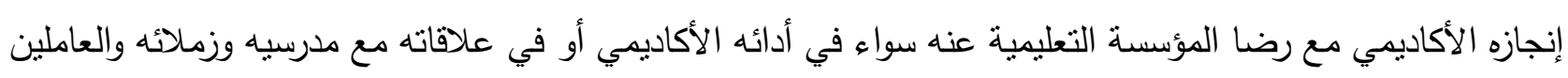
بالمؤسسة التعليمية . 
المعلومات البيوغرافية :

الجانب الشخصي:

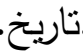

العمر ..... ....:العنوان:..

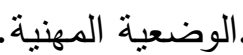

الوضعية العائلية: .

الاقتصادي.

المستوى الثقافي:

الجانب العائلي:

وضعية الوالدين على قيد الحياة...

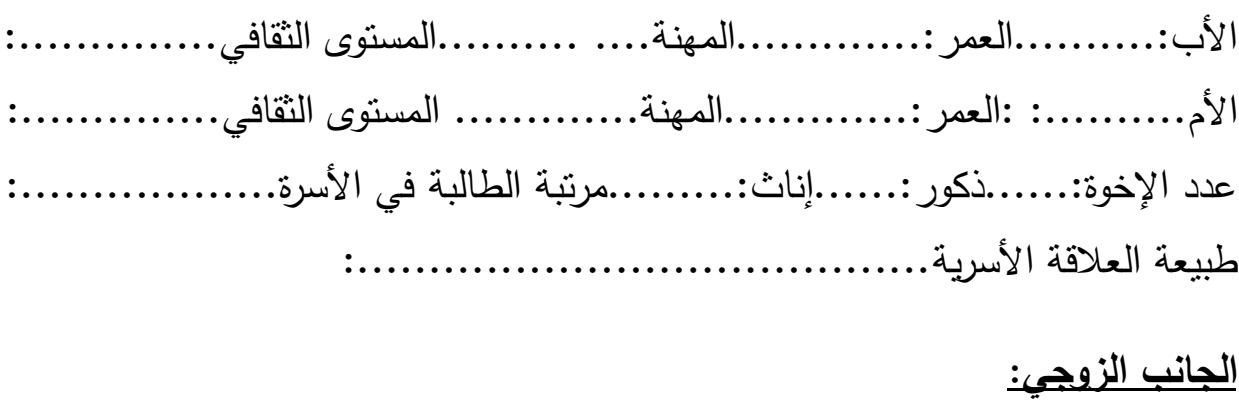

.طبيعة العلاقة بعد الزواج.......

تاريخ الزواج:.

.المستوى الثقافي.......

عمر الزوج:........المهنة:.............

الجانب الأسري:

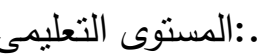

إناث

عدد الأولاد:

طبيعة العلاقة مع ....... عدد سنوات الممارسة:.....

:ذكور.

الجاتب المهني:المهنة: .

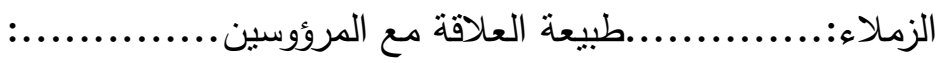

\begin{tabular}{|c|c|c|c|c|}
\hline بعد التعديل & تصلح & تصلح & 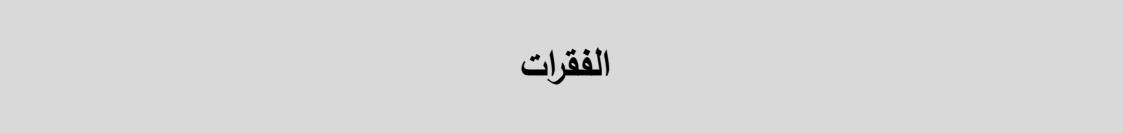 & ت \\
\hline & & & هل تتفق الدراسة مع ميولك واهتماماتك ؟ & 1 \\
\hline & & & هل تعتقدين أنه لا فائدة من التعليم إذا ما قورن بالمهن الأخرى؟ & $r$ \\
\hline & & & هل تشعرين بأن معظم طالبات المرحلة يريدون استبعادك من رحله مقرة سيقوم & $r$ \\
\hline & & & هل تعتقدين بأن معظم المواد الدراسية صعبه ويستحيل فههها ؟ & $\varepsilon$ \\
\hline & & & هل تقلقين لقترة طويلة إذا تعرضت لإهانة من أحد الناس؟ & 0 \\
\hline
\end{tabular}




\begin{tabular}{|c|c|c|c|c|}
\hline \multirow[t]{28}{*}{ تصد التعديل } & تصلح & تصلح & الفقرات & $ت$ \\
\hline & & & هل يتجاهلك زملاؤك في بعض المواقف؟ & 7 \\
\hline & & & هل ترتبكين بسرعة في أبسط الأمور؟ & V \\
\hline & & & هل تتفق دراستك مع ميولك واهتماماتك؟ & $\Lambda$ \\
\hline & & & هل تساعدين زملاؤك إذا طلبوا منك عونا ؟ & 9 \\
\hline & & & هل تبكين بسرعة إذا قابلتك مشاكل كثيرة؟ & 1. \\
\hline & & & هل تثعرين غالبا بالضيق مع بداية اليوم الدراسي ؟ & 11 \\
\hline & & & هل علاقتك بوالديك طيبة؛ ل & Ir \\
\hline & & & هل تمنيت أن تعود طفلا ؟ & Ir \\
\hline & & & هل لايك رغبة قوية في الدراسة ؟ & $1 \varepsilon$ \\
\hline & & & هل تشعرين بعواطف متناقضة من الحب والكراهية نحو بعض أفراد أسرتك ؟ & 10 \\
\hline & & & هل تعتقدين أن معظم المدرسين يشعرون نحوك بالمودة ؟ & 17 \\
\hline & & & هل تعتقدين بأنك كنت في الماضي أكثر سعادة مما أنت فيه الآن ؟ & IV \\
\hline & & & هل تفضلين التغيب عن الكلية كلما اسنطعت ذلك ؟ & 11 \\
\hline & & & هل تشعرين عادة بحرج من الاتصال بالمدرسين ؟ & 19 \\
\hline & & & هل تفضلين أن تعيش في عالم الأحلام بدلا من التفكير في الواقع؟ & $r$. \\
\hline & & & هل يرفض والدك آراعك في أغلب الأحيان ؟ & YI \\
\hline & & & هل تشعرين أن المدرسين أناس متعسفون ؟ & Yr \\
\hline & & & هل تثعرين بأن المستقبل مظلم بالنسبة لك؟ & Yr \\
\hline & & & هل فكرت في أن تؤدبي الطالبات الذين أساؤا إليك عن طريق انتظارهم خارج الكلية & $r \varepsilon$ \\
\hline & & & هل تثعرين أنك أقل من زميلاتك في النواحي العقلية ؟ & ro \\
\hline & & & هل تجدين تشجيعا من والدك على الدراسة والانتظام فيها ؟ & rq \\
\hline & & & هل سبق أن تمنيت لنفسك الموت في بعض الأحيان حتى تبعد عن الانيا وما فيها؟ & $r V$ \\
\hline & & & هل يعتقدان واللديكي أن معظم أفعالك خاطئة ؟ & $r \wedge$ \\
\hline & & & هل تفهمين غالبا الدوافع وراء تصرفاتك ؟ & rq \\
\hline & & & هل تذاكرين دروسك بانتظام أول بأول ؟ & $r \cdot$ \\
\hline & & & هل تتجنبين مقابلة الناس غالبا ؟ & 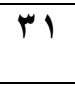 \\
\hline & & & هل تثعرين أن بعض قدراتك الذهنية أقل من زميلاتك في مثل سنك؟؟ & $r r$ \\
\hline
\end{tabular}




\section{دراسة مقارنة للتوجهات الفلسفية للتوافق الدراسي على وفق المتغيرات......}

\begin{tabular}{|c|c|c|c|c|}
\hline \multirow[t]{28}{*}{ تصد التعديل } & تصلح & تصلح & 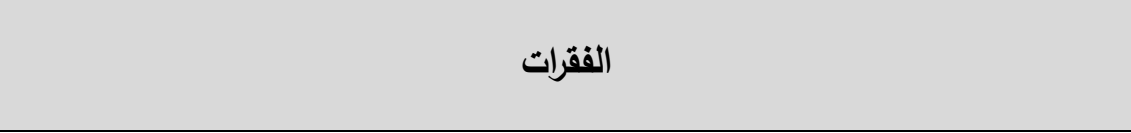 & $ت$ \\
\hline & & & هل تشعرين بالملل والضيق أثناء المذاكرة ؟ & $r r$ \\
\hline & & & إذا تعرضت لأهانه بعض الناس فهل تقلقي لفترة طويلة؟ & $r \varepsilon$ \\
\hline & & & هل تفضلين قضاء معظم أوقات الدراسة في اللعب؟ & ro \\
\hline & & & هل تشعرين بقلق دائم دون سبب ظاهر؟ & r \\
\hline & & & هل يشرد ذهنك كثيرا أثناء المحاضرة؟ & rv \\
\hline & & & هل تشعرين بالصداع ودوخة دون سبب؟ & r^ \\
\hline & & & هل تشعرين برغبة في النوم في معظم الأحيان؟ & rq \\
\hline & & & هل تتشاجرين كثيرا مع أخواتك؟ & $\varepsilon$. \\
\hline & & & هل تعتقدين أن معظم المدرسين يحبونك؟ & \&1 \\
\hline & & & هل تترددين كثيرا في أن تسأل المدرس عما لا تفهمينه ؟ & $\leqslant r$ \\
\hline & & & هل تحبين أن تتعاون مع أخوتك في مشروع ما؟ & $\leqslant r$ \\
\hline & & & هل تخثين الإجابة على سؤال المدرس بالرغم من أنتك تعرفين الإجابة الصحيحة؟ & $\leqslant \varepsilon$ \\
\hline & & & هل علاقتك بإخواتك طيبة؟ & $\leqslant 0$ \\
\hline & & & هل تثعرين بالتعب والإنهاك الثديد عند استيقاظك صباحا؟ & $\$ 7$ \\
\hline & & & هل تراودك الرغبة كثيرا في الخروج من الحصة أثناء الشرح؟ & $\varepsilon V$ \\
\hline & & & هل تشعرين أن والديك لا يهتمان بك؟ & $\leqslant \wedge$ \\
\hline & & & هل تجدين سهوله في تكوين الصداقات ؟ & $\$ 9$ \\
\hline & & & هل تعتمدين في أغلب الأحيان على الآخرين في حل واجباتك ؟ & o. \\
\hline & & & هل تضطربين اضطرابا شديدا عذد دخول الامتحان لدرجة تمنعك من المذاكرة؟ & 01 \\
\hline & & & هل تتضايقين من الالتزام بالنظام الجامعي ؟ & Or \\
\hline & & & هل تشعرين برغبة شديدة في الهرب من المنزل؟ & or \\
\hline & & & هل تثعرين بالذنب إذا تأخرت عن الدوام الجامعي؟ & $0 \leqslant$ \\
\hline & & & هل تثقين بنفسك في مواجهة المواقف الجديدة؟ & 00 \\
\hline & & & هل تشعرين بأن زميلاتك أسعد حظا منك في حياتهم المنزلية؟ & 09 \\
\hline & & & هل تثعرين برغبة في إتلاف الأثاث الدراسي إذا وجدت نفك وحيدا في قاعة & OV \\
\hline & & & 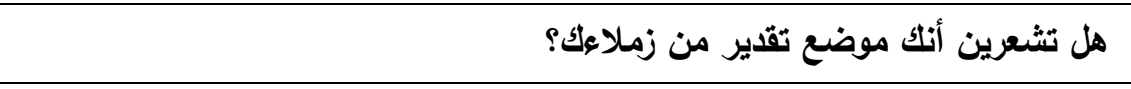 & $\theta \wedge$ \\
\hline & & & هل يقر الآخرون ما يجب أن تفعلينه غالبا؟ & 09 \\
\hline
\end{tabular}




\begin{tabular}{|c|c|c|c|c|}
\hline بعد التعديل & تصلح & تصلح & 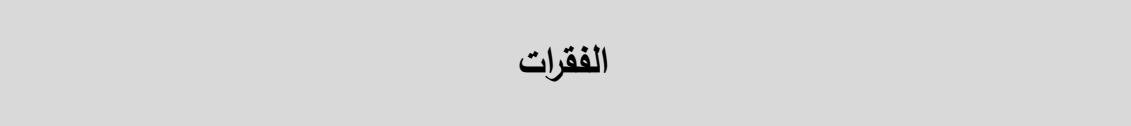 & $ت$ \\
\hline & & & هل تشعرين بأتك تعيسة ؟ & 7. \\
\hline & & & هل تحاولين الاستزادة من المعلومات من كتب خارجية؟ & 71 \\
\hline & & & هل تهتمين كثيرا بأمور البيت عندكم؟ & TY \\
\hline & & & اذا عرفت أنتك لن تضبطين وأنت تغشين فهل تفعلين ذلك؟ & 74 \\
\hline & & & هل تعتبرين نفسك شخصه مشاغبة في الفصل؟ & $7 \varepsilon$ \\
\hline & & & هل تثعرين بأن معظم أهدافك واقعية ويمكن تحقيقها ؟ & 70 \\
\hline & & & هل يرفض والدك آراؤك في أغلب الأحيان؟ & 79 \\
\hline & & & هل تعتقدين أن الكذب هو أفضل الطرق التي يجب أن يلجأ إليها الفرد للتخلص من & TV \\
\hline & & & هل تضعف عزيمتك عندما تفثلين لأول مره بعمل معين؟ & $7 \wedge$ \\
\hline & & & هل أنت راضية عن نفسك عموما؟ & 79 \\
\hline & & & هل تحاولين أن تصلي إلى أهد|فك مهما كلقك ذلك من جه وتعب؟ & $V$. \\
\hline
\end{tabular}

الملحق (r)

يوضح السادة الخبراء والمتخصصين

\begin{tabular}{|c|c|c|c|c|}
\hline 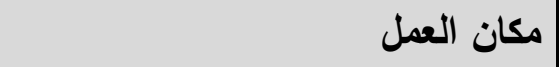 & الاختصاص & اللقب العلمي & 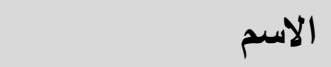 & $ت$ \\
\hline كلية التربية الرياضية/جامعة الموصل & القياس والتقويم & 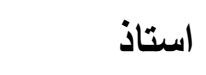 & د.هاشم احمد سليمان & 1 \\
\hline كلية التربية الرياضية/جامعة الموصل & القياس والتقويم & 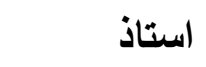 & لد ـمكي محمود & r \\
\hline كلية التربية الرياضية/جامعة الموصل & القياس والتقويم & 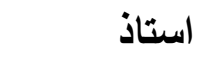 & لد.عبد الكريم قاسم & $r$ \\
\hline كلية التربية الرياضية/جامعة الموصل & القياس والتقويم & 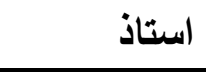 & د.ضرغام جاسم محمد & $\varepsilon$ \\
\hline كلية التربية الرياضية/جامعة الموصل & القياس والتقويم & استاذ مساعد & د.سبهان محمود & $\bullet$ \\
\hline كلية التربية الرياضية/جامعة الموصل & علم النفس & استاذ مساعد & د.نغم محمود & 7 \\
\hline كلية التربية الرياضية/جامعة الموصل & علم النفس & استاذ مساعد & د.موئيد عبد الرزاق & $v$ \\
\hline
\end{tabular}

